\title{
Paisajes tradicionales asistidos por galerías drenantes: un patrimonio cultural y territorial amenazado
}

\author{
José Antonio López Fernández
}

Universidad de Murcia. Departamento de Geografía

jantoniolf@um.es

Recibido: marzo de 2021

Aceptado: mayo de 2021

Publicado: septiembre de 2021

\section{Resumen}

El uso del agua ha configurado paisajes a lo largo de la historia en ámbitos áridos y semiáridos, como es el caso de la Región de Murcia, gracias a los sistemas de galerías drenantes, que han permitido la creación de espacios regados y la configuración de un patrimonio territorial y cultural. Sin embargo, los sondeos profundos y los cambios en el territorio desde los años 80 del siglo XX están provocando el abandono de estos ingenios hidráulicos. La investigación trata de determinar las características de estos complejos de abastecimiento a través del análisis de documentación y el trabajo de campo. Los resultados muestran el paulatino abandono de estas construcciones, lo cual se traduce en la pérdida de paisajes históricos, caracterizados por la presencia de un patrimonio hidráulico singular. Se requiere su puesta en valor y la adopción de medidas para reconocer este legado patrimonial.

Palabras clave: galería drenante; qanat; patrimonio hidráulico; uso integral y sostenible del agua; cambios territoriales

Resum. Paisatges tradicionals assistits per galeries drenants: un patrimoni cultural $i$ territorial amenaçat

L'ús de l'aigua ha configurat paisatges al llarg de la història en àmbits àrids i semiàrids, com és el cas de la Regió de Múrcia, gràcies als sistemes de galeries drenants, que han permès la creació d'espais regats i la configuració d'un patrimoni territorial i cultural. No obstant això, els sondejos profunds i els canvis en el territori des dels anys 80 de segle XX estan provocant l'abandonament d'aquests enginys hidràulics. La investigació pretén determinar les característiques d'aquests complexos de proveïment mitjançant l'anàlisi de documentació i el treball de camp. Els resultats mostren el progressiu abandonament d'aquestes construccions, la qual cosa es tradueix en la pèrdua de paisatges històrics, caracteritzats per la presència d'un patrimoni hidràulic singular. Es requereix la seva valoració i l'adopció de mesures per reconèixer aquest llegat patrimonial.

Paraules clau: galeria drenant; qanat, patrimoni hidràulic; ús integral i sostenible de l'aigua; canvis territorials 
Résumé. Paysages traditionnels assistés par galeries de drainage : un patrimoine culturel et territorial menacé

L'utilisation de l'eau a façonné les paysages à travers l'histoire dans les zones arides et semiarides, comme c'est le cas de la Région de Murcie, grâce aux systèmes de galeries de drainage, qui ont permis la création d'espaces irrigués et la configuration d'un territoire et d'un héritage culturel. Cependant, les sondages profonds et les changements du territoire depuis les années $80 \mathrm{du} 20 \mathrm{eme}$ siècle ont provoqué l'abandon de ces dispositifs hydrauliques. La recherche tente de déterminer les caractéristiques de ces complexes d'approvisionnement, à travers une analyse documentaire et des travaux sur le terrain. Les résultats montrent l'abandon progressif de ces constructions, ce qui se traduit par la perte de paysages historiques, caractérisés par la présence d'un patrimoine hydraulique singulier. Leur valorisation et l'adoption des mesures sont nécessaires pour reconnaître cet héritage patrimonial.

Mots-clés: galerie de drainage; qanat; patrimoine hydraulique; utilisation intégrale et durable de l'eau; changements territoriaux

\section{Abstract. Traditional landscapes assisted by draining galleries: A threatened cultural and territorial heritage}

The use of water has shaped landscapes throughout history in arid and semi-arid areas, such as the Region of Murcia, thanks to the draining gallery systems, which have allowed the creation of irrigated spaces and the configuration of a territorial and cultural heritage. However, deep drilling and territory changes since the 1980s are causing the abandonment of these hydraulic devices. This research tries to determine the characteristics of these supply facilities, through documentation analysis and field work. The results show the gradual abandonment of these constructions, which leads to the loss of historical landscapes, characterized by the presence of a unique hydraulic heritage. Its enhancement and the adoption of measures to recognize this heritage legacy are required.

Keywords: draining gallery; qanat; hydraulic heritage; integral and sustainable water use; territorial changes

\section{Sumario}

$\begin{aligned} \text { 1. Introducción } & \text { 4. Resultados } \\ \text { 2. Marco teórico } & \text { 5. Conclusiones } \\ \text { 3. Metodología } & \text { Referencias bibliográficas }\end{aligned}$

\section{Introducción}

Los sistemas tradicionales de captación de aguas, del tipo galería drenante, con lumbreras o qanat (Goblot, 1979), constituyen ejemplos de un patrimonio cultural heredado, tanto de carácter material como inmaterial: material, por sus características constructivas, por estar adaptados a las condiciones geológicas y climáticas de cada espacio; e inmaterial, por los conocimientos y técnicas que el ser humano ha desarrollado, generación tras generación, 
Figura 1. Características constructivas generales de un sistema drenante

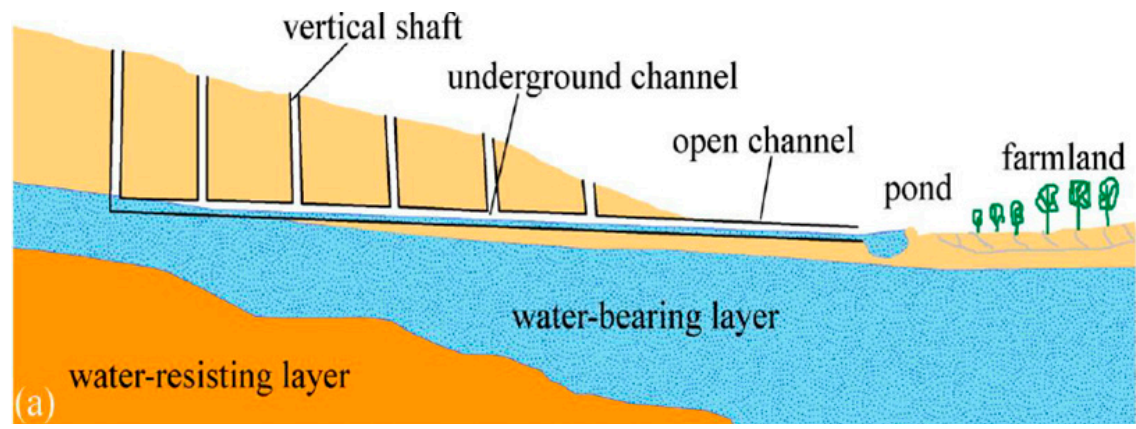

Fuente: Luo et al. (2014).

para hacer acopio de forma sostenible de un recurso escaso como es el agua (Gómez y Hervás, 2012).

Los sistemas de galerías drenantes pueden definirse como minados horizontales con una leve pendiente, construidos para captar y conducir flujos subterráneos y subálveos a la superficie, a partir de diferentes geoformas, como piedemontes, valles o cursos fluviales del tipo rambla (Antequera, 2015). No obstante, dentro de este conjunto, se pueden diferenciar diversas variedades (galerías con lumbreras, minas, socavones, zanjas, acequias de conducción subterráneas, qanat, kettara o khetara, etcétera) (Antequera, Iranzo y Hermosilla, 2014) en función de las características ambientales o de las finalidades de la construcción (figura 1).

Los sistemas drenantes son abundantes en ámbitos semiáridos en torno al mar Mediterráneo, exponente del conocimiento ancestral sobre captación y uso integral del agua (Zivdar y Karimian, 2020). Su principal utilidad ha sido históricamente el regadío, si bien antes de destinarse a la tierra se generaban otras posibilidades, lo que ha dado lugar a un uso integral del agua: fuentes para abastecimiento humano, pilones para el ganado o molinos para moler cereal (López, 2018). De ahí que su impacto territorial haya dado lugar a paisajes constituidos por la función sostenible de recursos hídricos obtenidos por medio de las galerías drenantes (Gerrard y Gutiérrez, 2018; Remini et al., 2014; Valipour et al., 2020).

Esta antigua técnica hidráulica (Murcia, 1958), indispensable para la subsistencia y el abastecimiento de las diferentes sociedades asentadas alrededor del Mare Nostrum, permitió durante siglos el acopio de agua (eso sí, con mucho esfuerzo) en un territorio de escasas lluvias. Sin embargo, en muchos lugares, los actuales modos de obtener recursos hídricos — por medio de trasvases (como el del Tajo a la cuenca del Segura en España), la regulación de caudales a través de embalses y, sobre todo, la mejora de las técnicas de extracción a través de sondeos verticales — han influido en la degradación de este tipo de ingenios, al verse afectados los flujos o acuíferos subterráneos de los que captaban el agua. 
Así, muchos de los sistemas de galerías drenantes han quedado en desuso, lo que, unido al escaso conocimiento y consideración social, está motivando su progresivo abandono y destrucción (Iranzo et al., 2010).

En la Región de Murcia, situada al sureste de la península Ibérica, con una precipitación media que no alcanza los $400 \mathrm{~mm}$ anuales, con espacios que, incluso, están por debajo de los $300 \mathrm{~mm}$, la construcción y puesta en funcionamiento de este tipo de sistemas horizontales posibilitó la configuración de paisajes tradicionales articulados por el uso sostenible del agua, en contraste con paisajes semiáridos, destinados históricamente al cultivo en secano, monte o erial.

El trabajo de campo a lo largo de los últimos años ha posibilitado el estudio de multitud de sistemas drenantes y, concretamente, más de cincuenta galerías con lumbreras, muchas de ellas funcionales, que nutren espacios regados de mayor o menor envergadura (López, 2020a; 2020b). Sin embargo, el aumento de las demandas hídricas y las transformaciones territoriales están produciendo el abandono de estos complejos, un legado cultural e identitario de los territorios áridos y semiáridos.

Atendiendo a la preocupante situación que presentan los antiguos sistemas tradicionales de galerías y su patrimonio generado, la presente investigación se articula sobre la perspectiva de considerar las galerías con lumbreras de la Región de Murcia y sus paisajes asociados como patrimonio cultural y territorial. Los objetivos son: a) exponer las características y potencialidades de los paisajes generados por complejos hidráulicos, que constituyen modelos de captación tradicional; $b$ ) analizar su estado y las posibilidades de aplicar la legislación sobre patrimonio cultural de la Comunidad Autónoma de la Región de Murcia para la conservación y salvaguarda de algunos de estos sistemas drenantes.

\section{Marco teórico}

La producción de trabajos, entre finales del siglo XX y comienzos del XXI, ha avanzado en la caracterización de los sistemas de galerías drenantes. Cabe destacar las investigaciones de Hermosilla et al. (2004) y Hermosilla (2008), que diferencian los sistemas entre galerías situadas en áreas de montaña, galerías en áreas intermedias o piedemontes (geoformas donde se encuentra el qanat propiamente dicho) y galerías en cursos y terrazas fluviales, con la construcción de cimbras y zanjas. Otra propuesta es la realizada por Gil y Gómez (1993 y 2007), que, al analizar las galerías del sureste de España, diferencian entre sistemas filtrantes y drenantes - los primeros se localizan en depósitos de gravas en cursos de aguas intermitentes y los segundos en depósitos de glacis y piedemontes-. Antaño, otros autores han diferenciado el qanat de una mina, de modo que el primero es el que se construye a partir de un pozo madre y cuyas aguas han de ser conducidas a la superficie por medio de una galería horizontal (Martí, 1989; Ron, 1996).

En todo este tiempo, numerosos trabajos se han ocupado de la localización, el estudio tipológico y el uso tradicional del agua captada por sistemas de galerías drenantes (Murcia, 1958; López-Camacho et al., 2005; Vidal, 1989; 
Gamero et al., 2017; Barceló, 1983; 1986; Barceló y Carbonero, 1986; Barón y Carbonero, 1987; Ron, 1996; Pocklington, 1988; Iranzo et al., 2010; Hermosilla et al., 2004; Roth y Schütt, 2001; Gil y Gómez, 1993; Gil, 2007; Gómez et al., 2007; Castejón, 2014; López, 2009; 2015; 2020; Gómez y López, 2006; Pelegrín, 2006; 2010; Pelegrín y García, 2007; Gris y Gris, 2002; Gómez, 2004a; 2004b; López et al., 2015). Además, también se han realizado estudios comparativos entre los sistemas drenantes encontrados en la España oriental y otros territorios bañados por el Mediterráneo (Pérez, 2005; López-Camacho, 2001; Hermosilla e Iranzo, 2014; Fansa et al., 2017).

Se trata, pues, de una técnica ancestral, utilizada no solo en la España mediterránea, sino en otras partes del mundo, sobre todo allí donde las condiciones climáticas no permiten disponer de caudales de aguas superficiales con carácter permanente. No obstante, todos los indicios señalan que este ingenio hidráulico se empezó a implementar en el antiguo territorio persa, en las zonas de Asia occidental (Al Karaimeh, 2019), norte de Egipto y Arabia (Wilkinson, 1977), para después expandirse a otras partes del mundo, debido al desarrollo de las rutas comerciales y el aumento de los contactos entre diferentes sociedades y culturas (Voudouris et al., 2019).

La presencia de estas captaciones es considerable en diferentes ámbitos, como en el sur de Italia, en numerosas áreas de los Balcanes y Grecia (Voudouris et al., 2019), en áreas de la actual Turquía (Ciftci y Leventeli, 2017) o en distintos países de América Central y del Sur (Palerm, 2004; Gómez, 2014). En la cuenca de Turpán, China, los sistemas drenantes, denominados karez, han sido (y continúan siendo) elementos indispensables para el desarrollo social y económico de muchas comunidades locales, con más de 400 galerías funcionales (Mächtle et al., 2019). En Irán (Megdiche-Kharrat et al., 2019), muchos territorios se configuran a partir del uso de más de 3.000 galerías drenantes. Están presentes en varias islas del ámbito canario, fundamentalmente de tipo mina (Santamarta, 2009), y en lugares más áridos, como en Tafilalet (al sur de Marruecos), donde las khetaras han posibilitado durante siglos la constitución de verdaderos oasis en medio del desierto. Actualmente, la mayor parte de ellas están en desuso y se han reconvertido en un reclamo turístico (Muñoz, 2012; Hmidani y Sguenfle, 2018). En la Región de Murcia, varios complejos aportan los recursos necesarios en diferentes espacios regados, lo que evidencia el interés ambiental y económico que supone la conservación y explotación sostenible de los sistemas funcionales (López, 2020a y 2020b).

Sin embargo, desde la perspectiva de esta investigación, se han de destacar los sistemas de foggaras de Tuat y Ti-dikeltse (Argelia), reconocidos desde 2018 como patrimonio cultural inmaterial por la UNESCO, por configurar un modelo de salvaguarda de los conocimientos y técnicas que vienen realizando los medidores de agua o alguaciles de este territorio, lo que también incide en la conservación de numerosos ejemplos de aprovechamientos hidráulicos del tipo galería.

En España, se han producido investigaciones de sistemas drenantes desde un enfoque patrimonial y territorial (Hermosilla e Iranzo, 2017; Hermosilla 
et al., 2012; Iranzo et al., 2010; Gil, 2009). En estos trabajos se pone de manifiesto el valor patrimonial de las infraestructuras hidráulicas de captación, conducción y gestión como parte de la identidad de la población y del territorio. En este sentido, Fansa et al. (2017: 295) destacan la consideración patrimonial de estos enclaves «a consecuencia de diversos factores históricos, sociales, funcionales y, en la mayoría de las ocasiones, paisajísticos. Las galerías y sus sistemas de regadío asociados son un factor de creación de paisaje y forman parte del patrimonio hidráulico». Constituyen, pues, un ejemplo de la relación que el ser humano ha tejido con su entorno otorgándole un carácter cultural y erigiéndose como bien patrimonial, como Blanco y Vela (2020) han reflejado en su estudio sobre las minas de agua en los montes de Málaga.

La investigación en el ámbito internacional destaca numerosos factores como amenazas de este patrimonio territorial y cultural: la despoblación del medio rural, la explotación del subsuelo como consecuencia de las posibilidades de extracción de agua por medio de sondeos verticales, cambios en los usos tradicionales de los suelos, así como la reducida atención que, desde el ámbito social, se presta en la actualidad a la conservación y salvaguarda de estos ingenios. Esta situación pone de manifiesto la necesidad de medidas que den a conocer y protejan la presencia del patrimonio cultural hidráulico, donde sobresalen construcciones y paisajes relacionados con el uso tradicional del agua.

Así pues, resulta de interés la relación patrimonial de los sistemas de acopio tradicionales a partir de galerías drenantes no solo desde el punto de vista material (infraestructura, materiales, espacios, etcétera), sino también desde la perspectiva inmaterial. En este sentido, la UNESCO, tras la Convención para la Salvaguardia del Patrimonio Cultural Inmaterial en 2003, identificó elementos de este patrimonio: las tradiciones y expresiones orales, incluido el idioma como vehículo del patrimonio cultural material; las artes del espectáculo; los usos sociales, rituales y actos festivos; los conocimientos y usos relacionados con la naturaleza y el universo, y las técnicas artesanales tradicionales.

\section{Metodología}

El enfoque metodológico que se utiliza es el que concierne al análisis geográfico, para comprobar la influencia que tiene el patrimonio hidráulico en la configuración del territorio y su impronta paisajística. A partir del análisis bibliográfico y el estudio de campo (localización, estudio cartográfico y análisis directo, catalogación y comparación, etcétera), se pretende poner de manifiesto el valor patrimonial y espacial de los sistemas drenantes, que dan lugar a paisajes culturales relacionados con el uso integral del agua en ámbitos semiáridos. Se examinan las características de las construcciones hidráulicas, representativas de una costumbre que tiene lugar en casi todas las comarcas de la Región de Murcia, y que se extiende, con las consiguientes particularidades, a los diversos territorios del ámbito mediterráneo.

En el análisis de estos aprovechamientos, se ha determinado su localización geográfica, y se ha diferenciado entre áreas de piedemonte, valles, terrazas y 
cursos del tipo rambla (Hermosilla, 2008; Gil y Gómez, 1993; 2007). A su vez, se recogen otros datos de interés, como el estado de conservación de los sistemas y la accesibilidad al mismo, información necesaria para la toma de posibles medidas para su salvaguarda y protección.

Respecto al estado de conservación de estas infraestructuras, se categoriza entre un estado bueno (sistemas que están funcionales en los que se ejecutan tareas de mantenimiento), aceptable (galerías que, aunque no están en uso, su puesta en marcha requeriría solamente tareas de limpieza y conservación) y en ruinas (para aquellos complejos que están sin uso y presentan la destrucción, caída o colapso de alguno de sus elementos, lo que requeriría trabajos de restauración).

Para el estudio de cada uno de los sistemas drenantes realizado a lo largo de los últimos años, se ha utilizado una ficha en la que se recoge toda la información señalada anteriormente. La mayor parte de la misma se ha tomado durante las fases del trabajo de campo. Otros aspectos, como los datos de localización o el caudal, se realizan posteriormente con ayuda de cartografía digital y la consulta a comunidades de regantes u organismos como la Confederación Hidrográfica del Segura, respectivamente. Toda esta información ha sido volcada a una base de datos con el programa Excel, que permite el tratamiento comparado de las variables del conjunto de aprovechamientos tradicionales.

Por otro lado, se ha procedido a analizar las características y concepciones actuales del patrimonio cultural (Mayordomo y Hermosilla, 2019), que emanan de las reuniones y convenciones que se han realizado en el ámbito internacional en las últimas décadas. Se ha prestado atención a la legislación regional de la Comunidad Autónoma de la Región de Murcia en cuanto al ordenamiento jurídico, clasificación y medidas de protección del patrimonio cultural, y se relaciona y justifica la posibilidad de incluir en la misma los sistemas drenantes junto a los paisajes generados por el uso sostenible de sus aguas.

Por tanto, el marco metodológico de este trabajo se apoya en la importancia del conocimiento geográfico para poner en valor el patrimonio cultural relacionado con el uso secular del agua en el ámbito mediterráneo (Hermosilla e Iranzo, 2014). Numerosos estudios aseveran la escasa conciencia social sobre los elementos del patrimonio hidráulico, por lo que se hace necesario justificar la importancia histórica y geográfica de las manifestaciones culturales que dan sentido a la configuración de estos territorios.

\section{Resultados}

\subsection{Estado de galerías drenantes en la Región de Murcia}

La figura 2 muestra la importancia de los sistemas drenantes y filtrantes del territorio murciano. El total de ingenios hidráulicos analizados asciende a 55, cifra a partir de la cual se han elaborado comparaciones cuantitativas y cualitativas, en cuanto a su estado de conservación, localización geográfica, características y caudales. 
Se puede observar mayor concentración en territorios carentes de aguas superficiales continuas (figura 2 y tabla 1). Las comarcas del Altiplano, donde reciben la denominación de minados con espejuelos, y el Campo Alto de Lorca (López, 2009) son las más representativas, mientras que en el valle del Segura y la comarca del Noroeste apenas se dan este tipo de sistemas de captación. En el primer caso, porque el abastecimiento tradicional proviene de las aguas del río Segura por medio de azudes y norias; en el segundo, por la presencia de fuentes y manantiales que, a lo largo del tiempo, han brotado por su pie, sin necesidad de ingenios que aumentasen los recursos disponibles (López y Sánchez, 2010).

La localización geográfica de cada aprovechamiento, que se refleja con la numeración de la figura 2, se correlaciona con la información expuesta en la tabla 1.

A partir de los datos, se puede observar que en la actualidad las galerías que están en desuso, afectadas en su mayor parte por un aumento de la explotación de recursos subterráneos, son superiores a aquellas que se mantienen funcionales (el 56,37\% frente al 43,63\% que están en uso) (tabla 2).

Sin embargo, de los 31 sistemas que no se encuentran en uso se ha evidenciado que $17(54,84 \%)$ ofrecen condiciones aceptables. Si se volviese a captar agua, en la mayor parte de los casos al reducir la sobreexplotación de acuíferos, bastaría con ejecutar tareas de limpieza y revisión del sistema. En cambio, $14(45,16 \%)$ muestran un estado de ruina, bien por la destrucción de la bocamina, por el taponamiento de una o varias lumbreras o por el colapso de la galería, lo cual determinaría realizar obras de restauración en el supuesto de su rehabilitación. De este modo, las galerías que no están en uso, aun aquellas con un estado de conservación aceptable, presentan un elevado grado de vulnerabilidad.

En cuanto a los sistemas funcionales, estos aportan, en el conjunto regional, un caudal medio superior a los $13 \mathrm{hm}^{3}$, con un claro protagonismo de la galería de Ojos de Luchena (Lorca) (López, 2020b), seguida por el Caño y Contracaño (Puerto Lumbreras). Si bien el resto de los sistemas funcionales ofrecen cifras más modestas, son de gran interés geográfico y social (tabla 3).

Por su parte, los sistemas no funcionales languidecen en muchos territorios, sobre todo en el Altiplano de Jumilla-Yecla, donde se utilizaron para el regadío de numerosas hectáreas de huertas y campos que rodean las principales entidades de población (Morales, 2007), en la comarca de Mula, la depresión intramontana del Guadalentín o el Campo Alto de Lorca (figura 3).

Los ambientes donde se localizan los sistemas de galerías son diversos (tabla 4), aunque con un factor común, como es el predomino en ambientes secos y alejados del dominio de cursos de agua, que, en este territorio, está constituido por el río Segura y los valles de sus principales afluentes (Argos, Quipar y Mula, principalmente).

La mayor concentración de sistemas se da en piedemontes, sobre todo en el Altiplano Jumilla-Yecla y el Campo Alto de Lorca $(53,33 \%)$. Se trata de sistemas propiamente identificados como qanats (Hermosilla, 2008). 
Figura 2. Localización de galerías con lumbreras en la Región de Murcia, diferenciadas según su funcionalidad actual

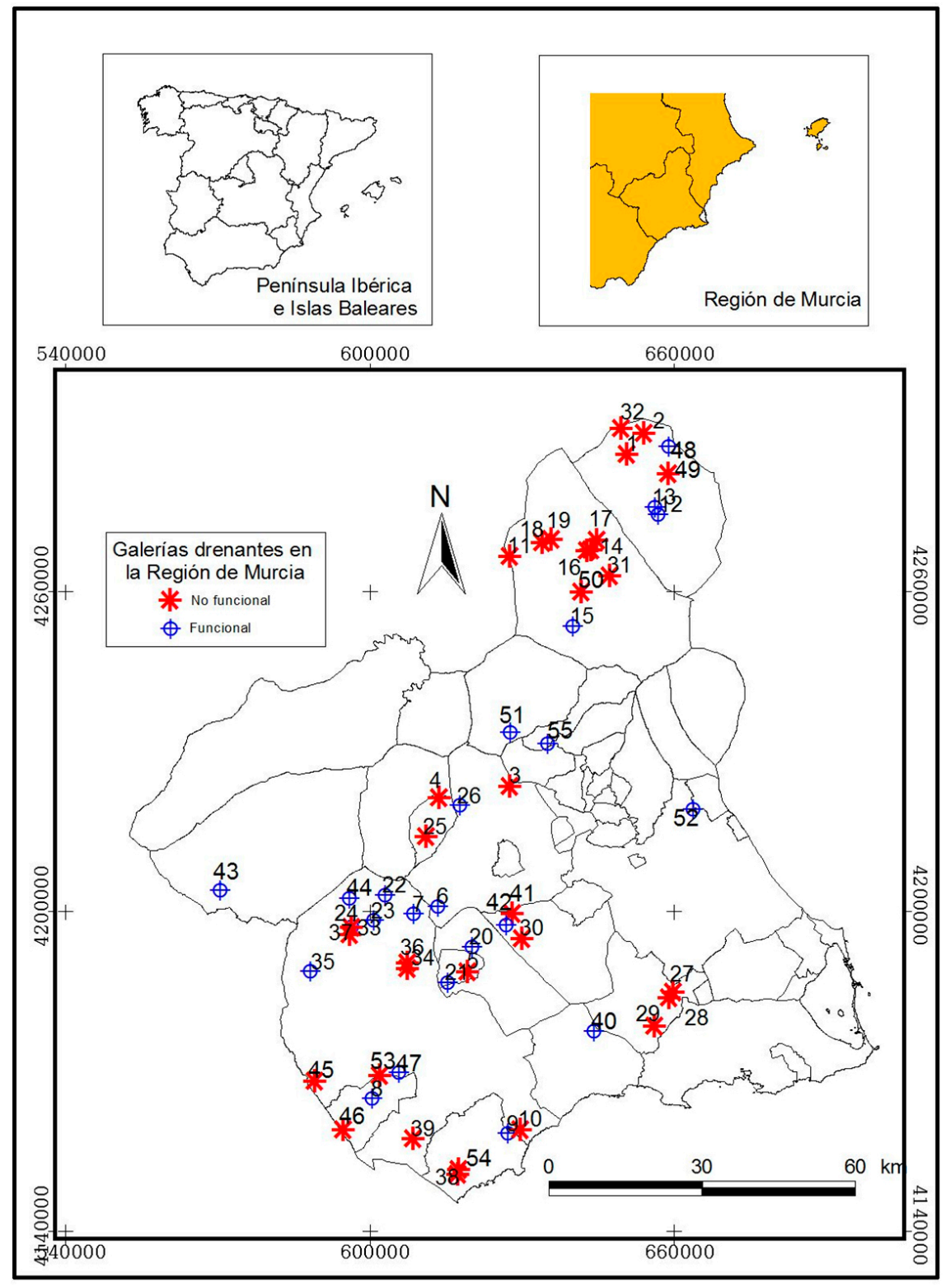

Fuente: elaboración propia. 
Tabla 1. Características constructivas y patrimoniales de los sistemas drenantes estudiados en el ámbito de la Región de Murcia

\begin{tabular}{|c|c|c|c|c|c|c|c|c|}
\hline N. ${ }^{\circ}$ & Denominación & UTM X & UTM Y & Uso* & $\begin{array}{l}\text { Estado } \\
\text { conserva }\end{array}$ & Situación & Municipio & Elementos anexos \\
\hline 1 & El Pulpillo & 655010,97 & 4284366,82 & N.F. & Aceptable & Piedemonte & Yecla & $\begin{array}{l}\text { Balsa para regadío, decantadores } \\
\text { y abrevadero }\end{array}$ \\
\hline 2 & Las Tobarrillas & 658392,21 & 4288482,01 & N. F. & Aceptable & Piedemonte & Yecla & Balsa, lavadero y abrevadero \\
\hline 3 & Veto & 632176,18 & 4219212,62 & N. F. & En ruinas & Piedemonte & Mula & Balsas para regadío \\
\hline 4 & Las Fontanicas & 618364,11 & 4217042,03 & N. F. & En ruinas & Piedemonte & Bullas & Balsas para regadío \\
\hline 5 & $\begin{array}{l}\text { Cabezo de los } \\
\text { Molinos }\end{array}$ & 623841,57 & 4182865,4 & N. F. & Aceptable & Piedemonte & Aledo & Balsas para regadío y molinos \\
\hline 6 & $\begin{array}{l}\text { Fuente de los } \\
\text { Tornajos }\end{array}$ & 618056,26 & 4195557,99 & $\mathrm{~F}$ & Bueno & Piedemonte & Mula & Balsa, abrevadero y lavadero \\
\hline 7 & $\begin{array}{l}\text { Zarzadilla de } \\
\text { Totana }\end{array}$ & 613312,52 & 4194071,61 & $\mathrm{~F}$ & Bueno & Piedemonte & Lorca & $\begin{array}{l}\text { Depósito, caños, lavadero, balsa, } \\
\text { conducción con acueductos }\end{array}$ \\
\hline 8 & $\begin{array}{l}\text { Caño y Contra- } \\
\text { caño }\end{array}$ & 605227,45 & 4157857,32 & $\mathrm{~F}$ & Bueno & Rambla & $\begin{array}{l}\text { Puerto Lum- } \\
\text { breras }\end{array}$ & Balsas, caños, abrevadero y molino \\
\hline 9 & El Garrobillo & 631682,55 & 4150995,64 & $\mathrm{~F}$ & Bueno & Piedemonte & Águilas & Balsa y abrevadero \\
\hline 10 & El Cantar & 634194,74 & 4151899,24 & N. F. & Aceptable & Piede. y rambla & Lorca & Balsa, aljibe y lavadero \\
\hline 11 & $\begin{array}{l}\text { Los Pinos, } \\
\text { Montesinos }\end{array}$ & 632146,25 & 4264318,36 & N. F. & Aceptable & Piedemonte & Jumilla & Balsa y abrevadero \\
\hline 12 & Fuente Negra & 660997,65 & 4272450,74 & $\mathrm{~F}$ & Bueno & Piedemonte & Yecla & Balsa y baños \\
\hline 13 & $\begin{array}{l}\text { Fuente } \\
\text { del Álamo }\end{array}$ & 660488,18 & 4273873,11 & $\mathrm{~F}$ & Bueno & Piedemonte & Yecla & Balsa, decantador y lavadero \\
\hline 14 & Los Estanquicos & 648079,25 & 4265526,32 & N. F. & Aceptable & Rambla & Jumilla & Balsa para regadío \\
\hline 15 & $\begin{array}{l}\text { Partido de } \\
\text { Ios Álamos }\end{array}$ & 644443,68 & 4250551,25 & $\mathrm{~F}$ & Bueno & Piedemonte & Jumilla & Balsa, aljibe y lavadero \\
\hline 16 & La Alquería & 647174,22 & 4265408,67 & N. F. & Aceptable & Piedemonte & Jumilla & Fuente pública y balsa \\
\hline 17 & Fuente del Pino & 649215,37 & 4267458,94 & N. F. & Aceptable & Piede. y rambla & Jumilla & Balsa, lavadero y abrevadero \\
\hline 18 & La Pedrera & 638475,26 & 4266998,99 & N. F. & Aceptable & Piedemonte & Jumilla & Balsa y aljibe \\
\hline 19 & Las Puntillas & 640311,48 & 4267574,94 & N. F. & Aceptable & Piedemonte & Jumilla & Balsa y lavadero \\
\hline 20 & $\begin{array}{l}\text { Las Alquerías, } \\
\text { La Sierra }\end{array}$ & 624770,06 & 4187603,42 & $\mathrm{~F}$ & Bueno & Piedemonte & Totana & Balsas y decantadores \\
\hline 21 & Chichar & 619980,24 & 4180670,25 & $\mathrm{~F}$ & Bueno & Rambla & Aledo & Balsa y abrevadero \\
\hline 22 & $\begin{array}{l}\text { Pozos de la } \\
\text { Fuente, Avilés }\end{array}$ & 607650,63 & 4197800,60 & $\mathrm{~F}$ & Bueno & Rambla & Lorca & Balsa para regadío y lavaderos \\
\hline 23 & Venta de 0ssete & 605429,82 & 4192761,25 & $\mathrm{~F}$ & Bueno & Rambla y valle & Lorca & Balsa para regadío \\
\hline 24 & Casa Robles & 601164,21 & 4191500,57 & $\mathrm{~F}$ & Bueno & Piedemonte & Lorca & Balsa para regadío \\
\hline 25 & Ucenda & 615722,1 & 4209303,67 & N. F. & Aceptable & Terraza & Bullas & l \\
\hline 26 & Tuestas & 622331,54 & 4215354,68 & $\mathrm{~F}$ & Bueno & Piedemonte & Mula & Balsa para regadío y decantador \\
\hline 27 & $\begin{array}{l}\text { Balsa de los } \\
\text { Celdranes }\end{array}$ & 664146,8 & 4178860,12 & N. F. & En ruinas & Piedemonte & \multicolumn{2}{|c|}{ Fuente Álamo Balsa para regadío } \\
\hline 28 & $\begin{array}{l}\text { Margen izda. } \\
\text { Rambla Fuente } \\
\text { Álamo }\end{array}$ & 663308,94 & 4177666,57 & N. F. & En ruinas & Rambla & \multicolumn{2}{|c|}{ Fuente Álamo Balsa para regadío / desaparecida } \\
\hline 29 & $\begin{array}{l}\text { Rambla de la } \\
\text { Azohía. F. Álamo }\end{array}$ & 660363,09 & 4172107,44 & N. F. & En ruinas & Rambla & \multicolumn{2}{|c|}{ Fuente Álamo Balsa y abrevadero } \\
\hline
\end{tabular}


Tabla 1. Características constructivas y patrimoniales de los sistemas drenantes estudiados en el ámbito de la Región de Murcia (continuación)

\begin{tabular}{|c|c|c|c|c|c|c|c|c|}
\hline N. ${ }^{\circ}$ & Denominación & UTM X & UTM Y & Uso* & $\begin{array}{l}\text { Estado } \\
\text { conserva }\end{array}$ & Situación & Municipio & Elementos anexos \\
\hline 30 & Azaraque & 634537,01 & 4189311,14 & N.F. & En ruinas & Piedemonte & $\begin{array}{l}\text { Alhama } \\
\text { de Murcia }\end{array}$ & Balsas, molinos y baños \\
\hline 31 & Los Inques & 651636,93 & 4260517,29 & N.F. & Aceptable & Piedemonte & Jumilla & I \\
\hline 32 & $\begin{array}{l}\text { Fuente de la } \\
\text { Colorada }\end{array}$ & 653879,59 & 4289315,21 & N.F. & Aceptable & Piedemonte & Yecla & Balsa, abrevadero y aljibe \\
\hline 33 & Fuente Ordán & 601241,8 & 4191543,49 & N. F. & En ruinas & Piedemonte & Lorca & Balsa para regadío \\
\hline 34 & San Ricardo & 612119,53 & 4183471,97 & N.F. & En ruinas & Piedemonte & Lorca & Balsa para regadío \\
\hline 35 & 0jos de Luchena & 593031,5 & 4182785,26 & $\mathrm{~F}$ & Bueno & Rambla & Lorca & $\begin{array}{l}\text { Desagua en cauce. Nacimiento río } \\
\text { Luchena }\end{array}$ \\
\hline 36 & Torralba & 612096,12 & 4184624,28 & N. F. & En ruinas & Terraza & Lorca & $\begin{array}{l}\text { Depósitos de decantación y balsa } \\
\text { para regadío }\end{array}$ \\
\hline 37 & $\begin{array}{l}\text { Margen izda. Río } \\
\text { Turrilla }\end{array}$ & 600844,64 & 4190069,25 & N. F. & En ruinas & Terraza & Lorca & $\begin{array}{l}\text { Molinos hidráulicos y balsas para } \\
\text { riego }\end{array}$ \\
\hline 38 & Finca Las Cuevas & 621992,72 & 4143081,09 & N.F. & En ruinas & Terraza & Águilas & I \\
\hline 39 & La Escarihuela & 613235,18 & 4150061,19 & N. F. & En ruinas & Terraza & Lorca & $\begin{array}{l}\text { Depósitos de decantación y balsa } \\
\text { para regadío / desaparecida }\end{array}$ \\
\hline 40 & $\begin{array}{l}\text { Rambla de la } \\
\text { Pinilla }\end{array}$ & 648596 & 4171265 & N. F. & Aceptable & Terraza & Mazarrón & Balsa para regadío \\
\hline 41 & $\begin{array}{l}\text { Fuente de la } \\
\text { Perdiz }\end{array}$ & 630563,32 & 4193119,79 & N. F. & Aceptable & Piedemonte & $\begin{array}{l}\text { Alhama de } \\
\text { Murcia }\end{array}$ & Balsa para regadío \\
\hline 42 & Fuente del Hilo & 630351,03 & 4191288,66 & $\mathrm{~F}$ & Bueno & Piedemonte & $\begin{array}{l}\text { Alhama de } \\
\text { Murcia }\end{array}$ & Balsa para regadío \\
\hline 43 & $\begin{array}{l}\text { Galería de El } \\
\text { Moral }\end{array}$ & 569167,36 & 4205828,85 & $\mathrm{~F}$ & Bueno & Piedemonte & $\begin{array}{l}\text { Caravaca de } \\
\text { la Cruz }\end{array}$ & Lavadero y balsas \\
\hline 44 & Fuente La Mina & 599944,91 & 4192244,76 & $\mathrm{~F}$ & Bueno & Piedemonte & Lorca & Balsa para regadío \\
\hline 45 & Los Cegarras & 594547,38 & 4160182,81 & $\mathrm{~F}$ & Bueno & Rambla & Lorca & $\begin{array}{l}\text { Balsa para regadío, molino } \\
\text { y abrevadero }\end{array}$ \\
\hline 46 & Goñar & 599612,84 & 4150530,26 & N. F. & Aceptable & Rambla & $\begin{array}{l}\text { Puerto Lum- } \\
\text { breras }\end{array}$ & $\begin{array}{l}\text { Balsa, caños, lavadero } \\
\text { y abrevadero }\end{array}$ \\
\hline 47 & Béjar & 607671,21 & 4162258,61 & $\mathrm{~F}$ & Bueno & Rambla & $\begin{array}{l}\text { Puerto Lum- } \\
\text { breras }\end{array}$ & Balsa, abrevadero y lavadero \\
\hline 48 & Fuente del Pinar & 662810,27 & 4287116,89 & $\mathrm{~F}$ & Bueno & Valle & Yecla & Lavadero y abrevadero \\
\hline 49 & Hoyica del Río & 662758,72 & 4282251,11 & N.F. & Aceptable & Piedemonte & Yecla & I \\
\hline 50 & Las Hermanicas & 648256,89 & 4262270,45 & $\mathrm{~F}$ & Bueno & Piedemonte & Jumilla & Balsa para regadío \\
\hline 51 & Fuente del Rey & 631786319 & 4228021,04 & $\mathrm{~F}$ & Bueno & Piedemonte & Cieza & Balsa y abrevadero \\
\hline 52 & Los Cuadros & 666451,46 & 4215866,65 & $\mathrm{~F}$ & Bueno & Rambla & Murcia & Balsa para regadío y decantador \\
\hline 53 & Vilerda & 602912,33 & 4154945,28 & N. F. & En ruinas & Rambla & $\begin{array}{l}\text { Puerto } \\
\text { Lumbreras }\end{array}$ & Balsa para regadío \\
\hline 54 & Huerta del Abad & 621875,12 & 4141773,45 & N. F. & En ruinas & Piedemonte & Águilas & Balsa, abrevadero y aljibe \\
\hline 55 & Fuente de Benito & 638875,57 & 4227387,96 & $\mathrm{~F}$ & Bueno & Rambla & Abarán & Fuente, lavadero y abrevadero \\
\hline
\end{tabular}

* F: Funcional. N. F: No funcional.

Fuente: elaboración propia a partir del trabajo de campo e investigaciones de archivo. 
Tabla 2. Proporción entre sistemas funcionales y no funcionales

\begin{tabular}{llll}
\hline Estado & N. & $\%$ & Estado \\
\hline Sistemas drenantes funcionales & 24 & 43,63 & 24 (bueno) \\
Sistemas drenantes no funcionales & 31 & 56,37 & 17 (aceptable) \\
& & & 14 (ruina) \\
\hline Total & 55 & 100 & \\
\hline
\end{tabular}

Fuente: elaboración propia a partir del trabajo de campo e investigaciones de archivo.

Tabla 3. Aportes de los sistemas funcionales en la Región de Murcia en el año 2019

\begin{tabular}{llcr}
\hline & & \multicolumn{2}{c}{ Caudal } \\
\cline { 3 - 4 } Nombre & Municipio & L/s & $\mathrm{m}^{3 / a n ̃ o ~}$ \\
\hline Los Cegarras-Los Cotes & Puerto Lumbreras & 0,0416 & 1.314 \\
Fuente de los Tornajos & Mula & 0,82 & $2.5859,52$ \\
Zarzadilla de Totana & Lorca & 3 & 94.608 \\
Caño y Contracaño & Puerto Lumbreras & 66,5 & 2.100 .000 \\
El Garrobillo & Águilas & 14,72 & $464.209,9$ \\
Ojos de Luchena & Lorca & 10.000 & 10.000 .000 \\
Partido de Los Álamos & Jumilla & 0,5 & 12.000 \\
Fuente La Mina & Lorca & 11 & 346.896 \\
Fuente de Avilés & Lorca & $\mathrm{s} / \mathrm{d}$ & $\mathrm{s} / \mathrm{d}$ \\
Las Alquerías. La Sierra & Totana & 4 & 126.144 \\
Tuestas & Mula & 0,3 & $9.460,8$ \\
Pozos de la Fuente. Avilés & Lorca & 10 & 315.360 \\
\hline Total & & & 13.495 .852 \\
\hline
\end{tabular}

Fuente: Confederación Hidrográfica del Segura. Elaboración propia.

Tabla 4. Localización ambiental de los sistemas de galerías drenantes

\begin{tabular}{lrc}
\hline Localización ambiental & $\mathrm{N}^{\circ}$ & $\%$ \\
\hline Piedemonte & 32 & 53,33 \\
Rambla & 13 & 21,67 \\
Terraza & 6 & 10,00 \\
Valle & 1 & 1,67 \\
Mixtos & 3 & 5,00 \\
Total & 55 & 100 \\
\hline
\end{tabular}

Fuente: elaboración propia.

Luego estarían los conjuntos localizados en torno a cauces secos del tipo rambla (21,67\%), como ejemplos de sistemas filtrantes. Posteriormente, se constatan construcciones en áreas intermedias, como pueden ser terrazas (que no llegan a cruzar transversalmente el cauce, pero que obviamente aprovechan flujos subálveos, $10 \%)$ y áreas de valle $(1,67 \%)$. Por su parte, algunos sistemas están construidos en diferentes áreas, ya que su cabecera se encuentra en un glacis o piedemonte, mientras que su tramo final se sitúa en áreas deprimi- 
Figura 3. Lumbreras y bocamina de la Galería de El Moral (1 y 2); Lumbreras de la Pinilla (3) y Fontanicas (4), estas últimas sin uso en la actualidad
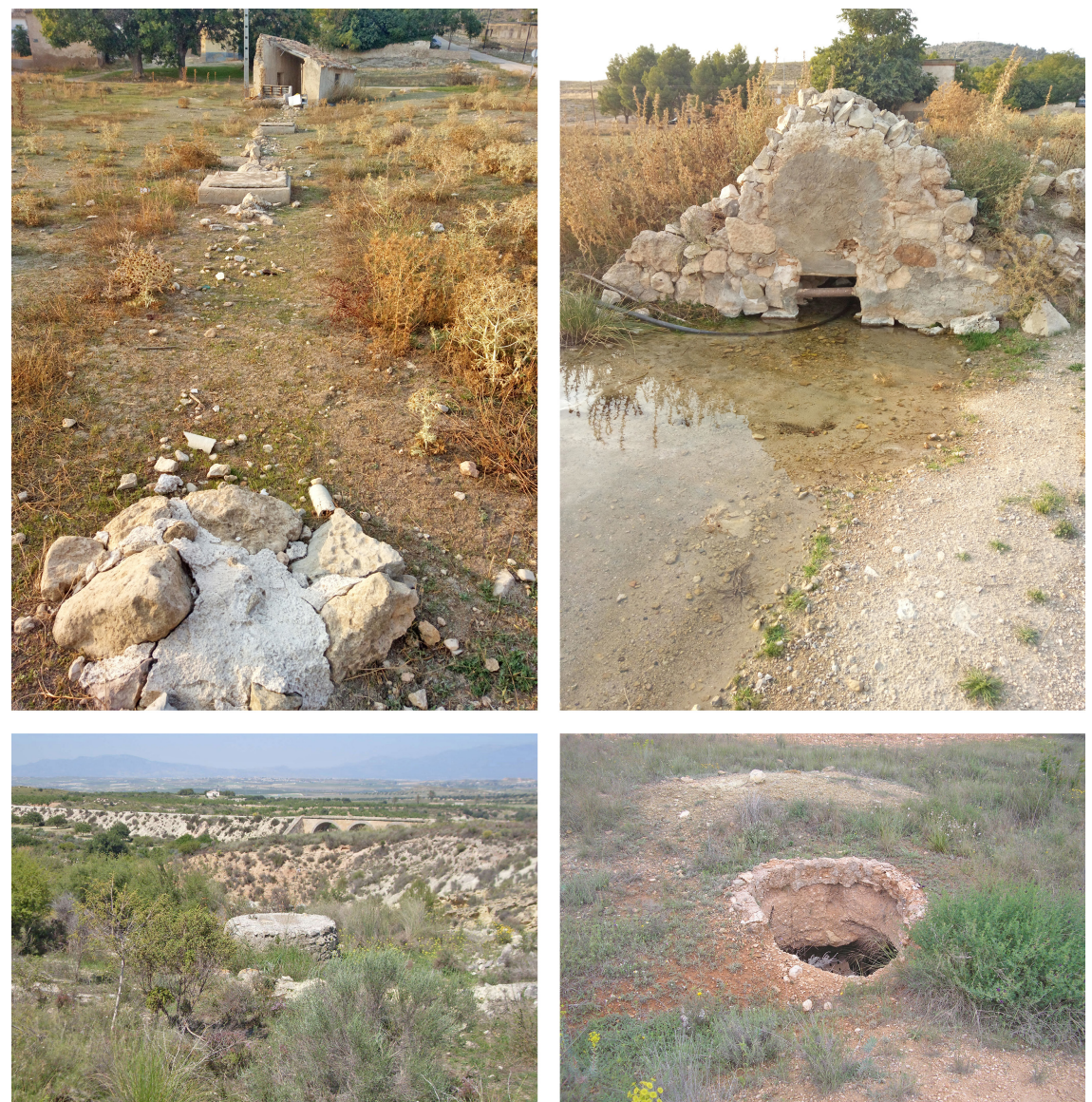

Fuente: elaboración propia.

das (5\%). Es el caso de las galerías de El Cantar, Fuente del Pino y Venta de Ossete.

Un aspecto sobresaliente de estos complejos es el patrimonio hidráulico generado en torno al uso de las aguas. Atendiendo a la tabla 5, se observa la diversidad del patrimonio material generado, con balsas de almacenamiento (48), situadas en la salida de las galerías con la finalidad de gestionar los recursos captados (figura 4). Estos elementos estaban presentes en la mayor parte de los complejos, salvo en algunos casos como Ucenda, que vertía sus aguas directamente al cauce del río Mula, o el citado de Ojos de Luchena, de iguales características. En algunos ejemplos, como Los Inques, las balsas eran sustituidas por aljibes (5). 
Tabla 5. Ingenios hidráulicos para aprovechar el agua de sistemas de galerías drenantes en la Región de Murcia

\begin{tabular}{lc}
\hline Elementos hidráulicos complementarios & $\mathrm{N} .^{\circ}$ \\
\hline Balsas & 48 \\
Abrevaderos & 17 \\
Lavaderos & 14 \\
Molinos & 6 \\
Decantadores & 5 \\
Aljibes & 5 \\
Baños & 2 \\
Fuentes & 2 \\
Depósitos & 1 \\
Acueductos & 1 \\
Total & 101 \\
\hline
\end{tabular}

Fuente: elaboración propia.

Figura 4. Balsas de los sistemas de Las Alquerías (1) y Veto (2), esta última no funcional
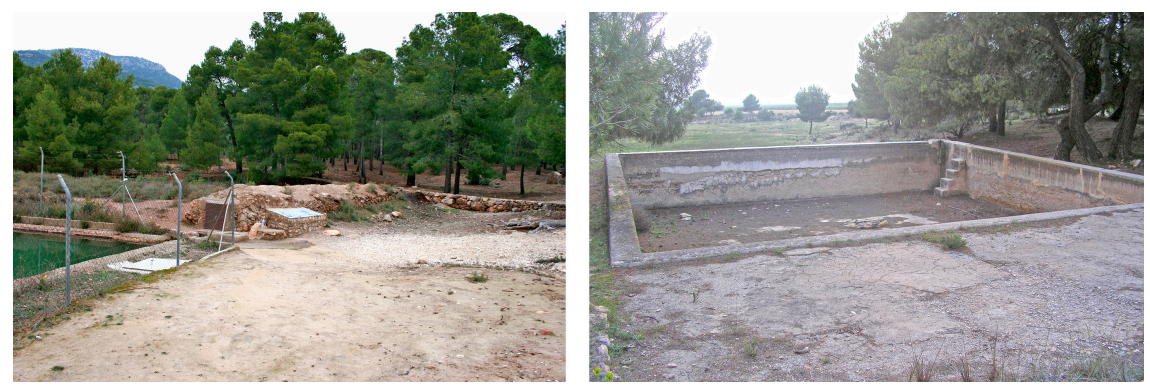

Fuente: elaboración propia.

En otros sistemas, es habitual la presencia de abrevaderos (17), utilizados para el abastecimiento del ganado, sobre todo en los complejos localizados cerca de veredas y cañadas. Varios ejemplos disponían de lavaderos, a cielo abierto algunos o a cubierto en pequeños edificios otros, como puede contemplarse en las galerías, hoy funcionales, de El Moral (Caravaca de la Cruz) o Zarzadilla de Totana (Lorca) (figura 5).

Para mejorar la calidad del agua, algunos sistemas contaban con decantadores en sus acequias, lo que permitía la retención de gravas y arenas. A su vez, en otros casos, el caudal era lo suficientemente importante para poner en marcha molinos hidráulicos, como sucedía en la Finca del Azaraque (Alhama de Murcia), en Zarcilla de Ramos (Lorca) o en Aledo y Totana (figura 6).

En otros ejemplos, también se disponían pilones y fuentes para el abastecimiento de boca de personas, lo que habla de la bondad de las aguas. En estos casos, las infraestructuras hidráulicas articulan el poblamiento de lugares como La Alquería o Fuente del Pino en Jumilla. Asimismo, es de destacar Zarzadilla 
Figura 5. Pilar y abrevadero en Zarzadilla de Totana (1) y lavadero tradicional bajo techo en la pedanía de El Moral (2), Caravaca de la Cruz
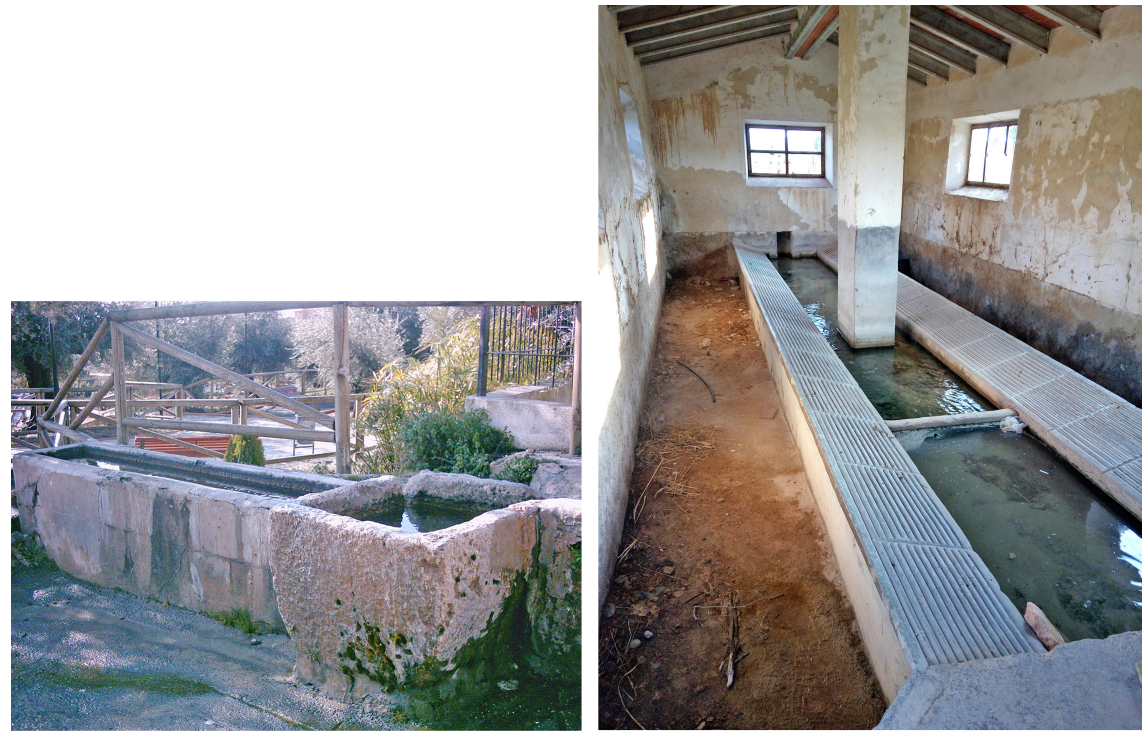

Fuente: elaboración propia.

Figura 6. Interior del minado de la Agualeja (1), molino hidráulico (2) y conducción por acueducto en la Rambla de los Molinos (3)
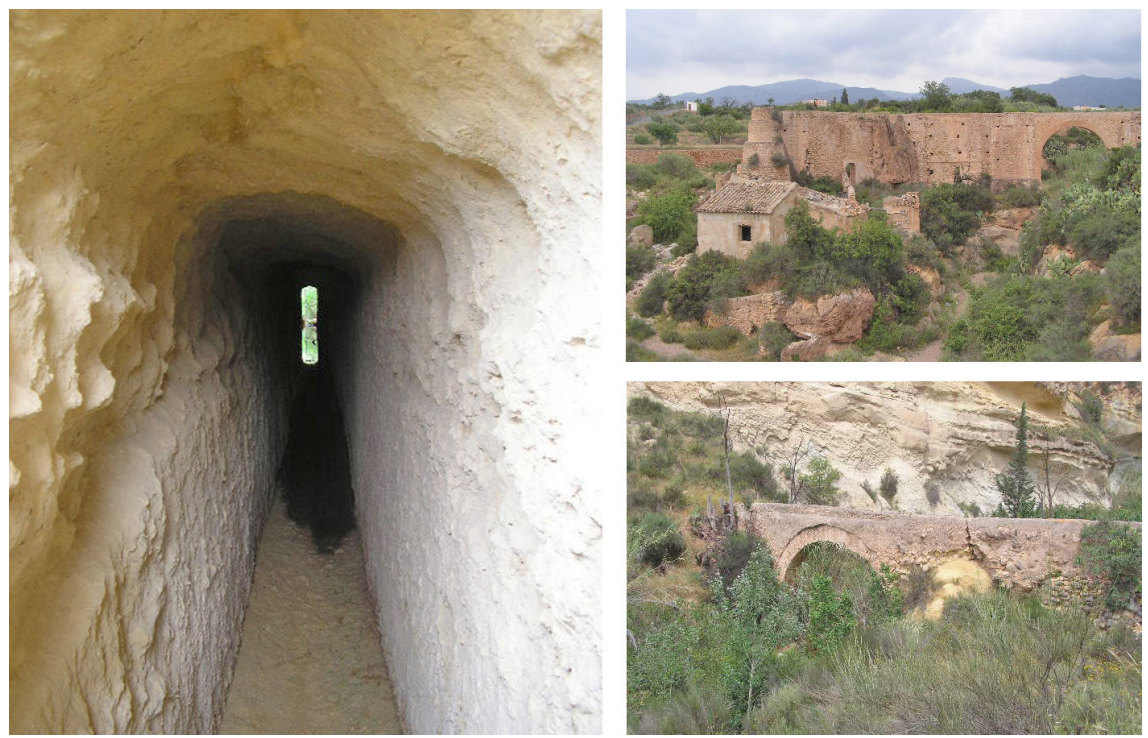

Fuente: elaboración propia. 
de Totana, donde puede hablarse de un sistema integral y sostenible, ya que el uso de las aguas era, y es, diverso, a través de diferentes construcciones (Gómez y López, 2006).

\subsection{Integración de los sistemas drenantes y los paisajes generados en el patrimonio cultural de la Región de Murcia}

La investigación geográfica e histórica pone de manifiesto la importancia e influencia de las construcciones hidráulicas de captación como exponente del patrimonio territorial. Un acervo cultural que, en la actualidad, puede ser considerado y puesto en valor por la sociedad. Al respecto, documentos y convenios internacionales pueden avalar la inclusión de este patrimonio en el conjunto de bienes culturales, en este caso en la Región de Murcia.

En la Conferencia General de la Organización de las Naciones Unidas para la Educación, la Ciencia y la Cultura, que tuvo lugar en la ciudad de París entre octubre y noviembre de 1972, se proclamó un acuerdo para la protección del patrimonio cultural y natural. En su artículo 1, se fijó la clasificación de patrimonio cultural entre tres figuras principales: monumentos, conjuntos y lugares, refiriéndose en este último punto a «obras del hombre u obras conjuntas del hombre y la naturaleza, así como las zonas, incluidos los lugares arqueológicos, que tengan un valor universal excepcional desde el punto de vista histórico, estético, etnológico o antropológico».

En la reunión de París también se propuso la necesidad de tomar medidas para proteger las manifestaciones culturales debido al valor universal y excepcional que presentan monumentos, conjuntos y lugares, por su importancia histórica, estética, etnológica y antropológica. Entre las medidas de protección que debían adoptar los estados firmantes de la convención (entre los que figura España), se incluía: «Identificar, proteger, conservar y revalorizar el patrimonio cultural y natural». No cabe duda de que, en este contexto, los complejos

Tabla 6. Factores singulares de los sistemas drenantes del mundo mediterráneo que justifican su conservación y salvaguarda, y su consideración como patrimonio cultural

\begin{tabular}{ll}
\hline Fundamentación & Razonamiento geográfico \\
\hline Tecnológicos & $\begin{array}{l}\text { Uso y difusión de técnicas mineras e hidráulicas a lo largo del tiempo, } \\
\text { que se han ido adaptando a las diferentes necesidades y características } \\
\text { fisiográficas y climáticas de cada territorio. }\end{array}$ \\
\hline Etnológicos & $\begin{array}{l}\text { Sociedades con amplia diversidad cultural, en torno a la cuenca del mar } \\
\text { Mediterráneo, pero relacionadas por la homogeneidad de las técnicas } \\
\text { hidráulicas de abastecimiento de agua. }\end{array}$ \\
\hline Paisajísticos & $\begin{array}{l}\text { Espacios de características homogéneas (paisajes de regadío tradicional) } \\
\text { creados a partir de sistemas drenantes, diferenciados de otros paisajes } \\
\text { áridos y semiáridos circundantes. Elementos identificativos propios. } \\
\text { Relaciones simbólicas y culturales en torno a la utilidad del agua. Uso } \\
\text { integral y sostenible del agua. }\end{array}$ \\
\hline
\end{tabular}

Fuente: elaboración propia. 
Tabla 7. Compromisos de los estados firmantes de la Convención sobre Patrimonio Cultural de París en 1972

c) desarrollar los estudios y la investigación científica y técnica y perfeccionar los métodos de intervención que permitan a un estado hacer frente a los peligros que amenacen a su patrimonio cultural y natural;

d) adoptar las medidas jurídicas, científicas, técnicas, administrativas y financieras adecuadas, para identificar, proteger, conservar, revalorizar y rehabilitar ese patrimonio, y

e) facilitar la creación o el desenvolvimiento de centros nacionales o regionales de formación en materia de protección, conservación y revalorización del patrimonio cultural y natural y estimular la investigación científica en este campo.

Fuente: Conferencia General de la Organización de las Naciones Unidas para la Educación, la Ciencia y la Cultura (1972).

hidráulicos pueden configurarse como elementos del patrimonio cultural debido a su valor arquitectónico, antropológico y como configurador del paisaje (tabla 6), propio de numerosos territorios mediterráneos (Fansa et al., 2017).

Además, se atribuye a los estados firmantes una serie de obligaciones para proteger y conservar el patrimonio cultural. Entre estos compromisos adoptados por los diferentes países, se recogen las siguientes situaciones (tabla 7).

En la reunión de París, también se incidió en prestar atención no solo a los ámbitos urbanos, sino también al patrimonio de los medios rurales.

Por su parte, en la Convención para la Salvaguarda del Patrimonio Arquitectónico de Europa, celebrada en diciembre de 1985 en Granada, se establecieron los siguientes bienes inmuebles como parte del patrimonio arquitectónico (tabla 8).

Si se tiene en cuenta la política de conservación fijada en 1985, según el artículo 10 de la Convención de Granada, el patrimonio arquitectónico debe

Tabla 8. Categorización de bienes inmuebles recogidos en la Convención para la Salvaguarda del Patrimonio Arquitectónico de 1985

\begin{tabular}{ll}
\hline Bienes inmuebles & Definición \\
\hline Monumentos & $\begin{array}{l}\text { Todas las realizaciones especialmente relevantes por su interés } \\
\text { histórico, arqueológico, artístico, científico, social o técnico, com- } \\
\text { prendidas las instalaciones o los elementos decorativos que cons- } \\
\text { tituyen parte integrante de estas realizaciones. }\end{array}$ \\
\hline Conjuntos arquitectónicos & $\begin{array}{l}\text { Grupos homogéneos de construcciones urbanas o rurales relevan- } \\
\text { tes por su interés histórico, arqueológico, artístico, científico, social } \\
\text { o técnico y suficientemente coherente como para ser objeto de una } \\
\text { delimitación topográfica. }\end{array}$ \\
\hline Sitios & $\begin{array}{l}\text { Obras combinadas del hombre y de la naturaleza, parcialmente } \\
\text { construidas y que constituyan espacios suficientemente caracte- } \\
\text { rísticos y homogéneos como para ser objeto de una delimitación } \\
\text { topográfica, relevantes por su interés histórico, arqueológico, social } \\
\text { o técnico. }\end{array}$
\end{tabular}

Fuente: artículo 1 de la Convención de Granada para la Protección del Patrimonio Arquitectónico. 
representar un objetivo general de la ordenación del territorio y deben existir medidas específicas de conservación y restauración. En este caso, se ha de considerar que los sistemas de captación y los paisajes generados, cada uno con sus características y particularidades, se ven reflejados en la categoría de «sitios culturales», en consonancia con la definición de lugares señalados en la Convención de París de 1972.

$\mathrm{Al}$ respecto, también resulta de interés considerar el Plan Nacional de Paisajes Culturales, aprobado por el Consejo de Patrimonio en 2012, dependiente del Ministerio de Educación, Cultura y Deporte de España, donde se reflejó la siguiente definición de paisaje cultural: «Resultado de la interacción en el tiempo de las personas y el medio natural, cuya expresión es un territorio percibido y valorado por sus cualidades culturales, producto de un proceso y soporte de la identidad de una comunidad» (MECD, 2012). Entre las categorías establecidas para la consideración de los paisajes culturales, se encuentran los espacios agrícolas y las infraestructuras hidráulicas que propician la construcción histórica del paisaje.

Por su parte, en la Región de Murcia entró en vigor la Ley 4/2007, de 16 de marzo, de Patrimonio Cultural de la Comunidad Autónoma de la Región de Murcia, con el fin de actualizar la Ley de Patrimonio Cultural de dicha región, que databa de 1992, amparada con el marco legislativo del desarrollo de su Estatuto de Autonomía. Así, en el preámbulo de la norma del año 2007, se expresa la necesidad de poner en valor las manifestaciones culturales propias de la región e interpelar las medidas necesarias para su conservación.

En esta directiva autonómica, se expone la clasificación de los bienes que integran el patrimonio cultural (tabla 9). Si bien son varios los apartados donde se pueden considerar los complejos hidráulicos, a nuestro criterio es el denominado Lugar de interés etnológico, dentro de la consideración de bien de interés cultural (BIC), el más apropiado para consignar este conjunto, configurado a partir del aprovechamiento integral del agua, junto con otros elementos

Tabla 9. Categorización prevista para el patrimonio cultural en la Región de Murcia

\begin{tabular}{ll}
\hline Categorías & Subcategorías y definiciones \\
\hline a) Bien de interés cultural (BIC) & Monumento \\
& Conjunto histórico \\
& Jardín histórico \\
& Sitio histórico \\
& Zona arqueológica \\
& Zona paleontológica \\
& Lugar de interés etnográfico \\
\hline b) Bienes catalogados por su & Muebles, inmuebles e inmateriales, de notable relevancia cultu- \\
relevancia cultural & ral pero no merecen protección derivada de BIC. \\
\hline c) Bienes inventariados & Muebles, inmuebles e inmateriales de destacado valor cultural \\
& pero sin merecer ser BIC ni bien catalogado. \\
\hline
\end{tabular}

Fuente: Ley 4/2007 de Patrimonio Cultural de la Comunidad Autónoma de la Región de Murcia. 
complementarios como balsas, abrevaderos o canales de conducción, que representan la relación histórica de la sociedad y su entorno, caracterizado por sus condiciones semiáridas.

Además de esta figura de protección, la legislación murciana también presenta las medidas de defensa de bienes catalogados por su relevancia cultural $\mathrm{y}$ de bienes inventariados.

Castejón y Canales (2016) localizaron 786 elementos catalogados por la Dirección General de Bienes Culturales, dependiente de la Consejería de Cultura, relacionados con el patrimonio hidráulico. Sin embargo, solo cinco de ellos se computan como mina y uno como galería, ninguno como bien de interés cultural.

Lo que más se aproxima a este nivel de protección corresponde a siete conjuntos declarados como BIC en la figura de lugar de interés etnográfico (a fecha de junio de 2021), de los cuales seis están relacionados con aprovechamientos hídricos.

De conformidad con la definición de lugar de interés etnográfico (BIC), los sistemas de galerías y sus espacios circundantes pueden considerarse dentro de esta categoría. Se ha de entender, por tanto, que las infraestructuras de galerías drenantes deben ser, por lo menos, inventariadas y catalogadas por la administración en el ámbito local y regional, ya que constituyen una manifestación tradicional de su historia.

Sobre Ojos de Luchena (tabla 10) hay constancia documental de que, desde principios del siglo XVII, la configuración del espacio de cultivo lorquino

Tabla 10. Propuesta de declaración de BIC del entorno de la Galería de Ojos de Luchena

\begin{tabular}{ll}
\hline Entorno & Propuesta de bien de interés cultural (categoría) \\
\hline Galería de Ojos de Luchena & $\begin{array}{l}\text { Lugar de interés etnográfico: paraje natural, conjunto de construc- } \\
\text { ciones o instalaciones vinculadas a formas de vida, cultura y activi- } \\
\text { dades propias de la Región de Murcia }\end{array}$
\end{tabular}

\begin{tabular}{l} 
Características \\
\hline - Conjunto de construcciones históricas, en un entorno natural, destinado a la captación de \\
agua. \\
- Técnica hidráulica intrínseca del territorio de la Región de Murcia en general y del ámbito \\
lorquino en particular, singular en ámbitos áridos y semiáridos de diversas partes del mundo. \\
- Reflejo de una población rural, propia de la cultura de la Región de Murcia, relacionada con el \\
aprovechamiento sostenible del agua a lo largo de la historia.
\end{tabular}

\section{Información contextual}

- Galería de filtración en el subálveo del río Luchena, en el estrecho de Pericay.

- Conjunto de canales de conducción.

- Paraje natural del río Luchena.

- Documentación histórica de actuaciones de construcción y ampliación de la galería, anterior al siglo XVII, con numerosos datos sobre inspecciones y actuaciones para aumentar la captación de caudales.

Fuente: elaboración propia. 
se estructuró gracias a la explotación de esta galería, un lugar que ha sufrido numerosas actuaciones desde hace siglos para aumentar el volumen de captación (Rodríguez, 1995; Pelegrín y García, 2007).

\section{Conclusiones}

Con el paso del tiempo, cada vez son más abundantes los sistemas de galerías drenantes en estado ruinoso. Por el contrario, las nuevas infraestructuras de agua generan una mayor disponibilidad y facilidad para el abastecimiento.

No obstante, a la luz de los trabajos de investigación sobre estos aprovechamientos tradicionales en el entorno de la Región de Murcia, se pone de manifiesto la importancia de una técnica ancestral y sostenible, y su impacto en el desarrollo de paisajes culturales junto a elementos anexos de indudable valor. Defendemos la consideración de los resultados que se aportan en este y en otros trabajos para que este tipo de ingenios, propios de la arquitectura hidráulica tradicional, sirvan para poner en valor estos ámbitos territoriales que muestran la cultura del agua, para la implementación de medidas que puedan proteger estas construcciones y la calidad de los paisajes rurales a que dan lugar.

El análisis de la documentación referente al patrimonio cultural evidencia que el legado histórico relacionado con el uso del agua es significativo en la Región de Murcia, extensible al resto de la fachada mediterránea. De todos modos, los sistemas de galerías drenantes y filtrantes apenas son considerados dentro del conjunto del patrimonio hidráulico, lo que redunda en su escaso reconocimiento social y, por tanto, en la falta de medidas de conservación y protección.

$\mathrm{Al}$ contrario, consideramos que se trata de un referente etnográfico y geográfico conformado por un saber hacer tradicional sostenible, y un factor fundamental en la configuración de un paisaje de carácter patrimonial, de gran relevancia en la Región de Murcia, en comarcas carentes de recursos hídricos superficiales.

\section{Referencias bibliográficas}

Al KARAIMEH, Sufyan (2019). «Maintaining desert cultivation: Roman, Byzantine, and Early Islamic water-strategies at Udhruh region, Jordan». Journal of Arid Environments, 166, 108-115. <https://doi.org/10.1016/j.jaridenv.2019.03.007>

ANTEQUERA, M. (2015). Las galerías drenantes en el sector oriental y suroriental de la Peninsula Ibérica. Identificación, análisis y gestión patrimonial. Tesis doctoral. Universidad de Valencia. Recuperado de <http://roderic.uv.es/handle/10550/43231>.

Antequera, M.; Iranzo, E. y Hermosilla, J. (2014). "Las galerías drenantes en España: cuantificación y clasificación tipológica de los sistemas horizontales de captación de aguas subterráneas. En: «Tribute to Thomas F. Glick». Irrigation, Society, Landscape. Valencia: Universitat Politècnica de València, 1.139-1.154. $<$ http://dx.doi.org/10.4995/ISL2014.2014.216> 
Barceló, M. (1983). "Qanat(s) a Al-Andalus». Documents d'Analisi Geográfica, 2, 3-22. Recuperado de <https://ddd.uab.cat/pub/dag/02121573n2/02121573n2p3.pdf>.

- (1986). «La qüestió de l'hidraulisme andalusí». En: Les aigües cercades (Els qanat(s) de l'illa de Mallorca). Palma de Mallorca: Institut d'Estudis Baleàrics, 9-36.

Barceló, M. y Carbonero, M. ${ }^{a}$ A. (1986). "Topografia i tipologia dels qanat(s) de l'illa de Mallorca». En: Les aigües cercades (Els qanat(s) de l'illa de Mallorca). Palma de Mallorca: Institut d'Estudis Baleàrics, 37-46.

BARÓN, A. y CARbONERO, Ma . A. (1987). "Las captaciones por gravedad, qanat(s): Situación actual y posibilidades de uso». IV Simposio de Hidrogeología, XI. IGME, Palma de Mallorca.

Blanco Sepúlveda, R. y Vela Torres, A. (2020). «Análisis de las minas de agua de los Montes de Málaga mediante criterios de carácter patrimonial». E-RPH, 25, 5-27. <https://doi.org/10.30827/e-rph.v0i25.17884>

Castejón, G. (2014). Galerías con lumbreras (qanats) en Fuente Álamo de Murcia. Sistemas históricos de captación y canalización de aguas. Fuente Álamo: Ayuntamiento de Fuente Álamo.

Castejón, G. y Canales, G. (2016). «El patrimonio hidráulico de la Región de Murcia y la necesidad de su puesta en valor mediante un memorial sobre la cultura del agua». En: García Marín, R.; Alonso Sarría, F.; Belmonte Serrato, F. y Moreno Muñoz, D. (eds.). XV Coloquio Ibérico de Geografía. Retos y tendencias de la Geografía Ibérica. Actas. Murcia: Asociación de Geógrafos Españoles, 458-467.

Ciftci, I. y Leventeli, Y. (2017). "Example of Qanats for the Sustainability of Groundwater Usage, Antalya-Turkey». Earth and Environmental Science, 95, 1-9. <https://doi.org/10.1088/1755-1315/95/2/022027>

Consejo DE EUROPA (1985). «Convención para la Salvaguardia del Patrimonio Arquitectónico de Europa». En: Cultura de Andalucía. Recuperado de <https://ipce. culturaydeporte.gob.es/dam/jcr:73f8d55e-17db-4676-9d80-962fb58eb3b7/1985convencion-granada.pdf> [consulta: 22 de marzo de 2021].

Fansa, G., Antequera, M. y Hermosilla, J. (2017). "Análisis comparativo de las galerías drenantes tunecinas y del sector oriental y suroriental español. Un modo de captación de aguas subterráneas en la cuenca mediterránea». Boletín de la Asociación de Geógrafos Españoles, 75, 279-317. <http://dx.doi.org/10.21138/bage.2502>

Gamero, F.; Recio, J.; García-Ferrer, A. y Borja, C. (2017). «Localización y caracterización de captaciones y antiguos qanats de abastecimiento a la ciudad de Córdoba desde Sierra Morena». Boletín de la Asociación de Geógrafos Españoles, 74, 417-435.

<http://dx.doi.org/10.21138/bage.2460>

Gerrard, C. y GuTiérrez, A. (2018). «El Qanat en España. Arqueología y medio ambiente». En: Berking, J. (ed.). Gestión del agua en las civilizaciones antiguas. Berlín: Edición Topoi, 197-226. <https://doi.org/10.17171/3-53>

GIL, E. (coord.) (2007). Sistemas locales de recursos propios de agua en la Región de Murcia. Minados y galerías. Murcia: Colección Usos del agua en el territorio. Universidad de Murcia.

- (coord.) (2009). Paisaje y patrimonio generados por galerías y minados en la Región de Murcia. Murcia: Colección Usos del Agua en el territorio. Universidad de Murcia. 
Gil, E. y Gómez, J. M. (1993). "Galerías con lumbreras en el Sureste de España». Papeles de Geografía, 19, 125-145. Recuperado de <https://revistas.um.es/geografia/article/view/44271>.

- (coord.) (2007). Modelos de sostenibilidad en el uso del agua en la Región de Murcia. Murcia: Colección Usos del Agua en el Territorio. Universidad de Murcia.

Goblot, H. (1979). Les Qanats. Une technique d'acqusition de l'eau. París-La HayaNueva York: Mouton Editeur.

Gómez, J. (2014). «El abasto de agua en la villa de Aguascalientes. El Acueducto del Cedazo. 1731-1891». Tzintzun. Revista de Estudios Históricos, 59, 13-52. Recuperado de <https://dialnet.unirioja.es/ejemplar/369448>.

Gómez, J. M. (2004a). Aprovechamiento integral del agua en la Rambla de Nogalte (Puerto Lumbreras-Murcia). Murcia: Colección Usos del agua en el territorio. Universidad de Murcia.

- (2004b). «Sostenibilidad de usos del agua en el territorio frontera de los antiguos reinos de Granada y Murcia». Papeles de Geografía, 40, 49-66. Recuperado de $<$ https://revistas.um.es/geografia/article/view/44551>.

Gómez, J. M.; Gil, E.; Martínez, R. y López, J. A. (2007). «Las estructuras de captación de agua mediante galerías con lumbreras en el Campo de Cartagena». Revista Murciana de Antropología, 14, 165-198. Recuperado de <https://revistas. um.es/rmu/article/view/107871>.

Gómez, J. M. y Hervás, R. M. (coord.) (2012). Patrimonio hidráulico y cultura del agua en el Mediterráneo. Murcia: Fundación Séneca. Campus Mare Nostrum. Agencia Española de Cooperación Internacional para el Desarrollo.

Gómez, J. M. y López, J. A. (2006). «Galerías con lumbreras en el área central de la Región de Murcia». Papeles de Geografía, 43, 31-59. Recuperado de <https:// revistas.um.es/geografia/article/view/43551>.

GrIS, L.; Solís, L. y GrIS, J. (2002). «El acueducto romano de Torralba. Caracterización funcional, hidrológica y aspectos socioeconómicos ligados a su explotación». Revista Alberca, 1, 171-209. Recuperado de <http://www.amigosdelmuseoarqueologicodelorca.com/alberca/pdf/alberca1/articulo12.pdf $>$.

Hermosilla, J. (dir.) (2008). Las galerías drenantes en España. Análisis y selección de qanat(s). Madrid: Ministerio de Medio Ambiente.

Hermosilla, J.; Antequera, M. e Iranzo, E. (2012). «Identificación, análisis, evaluación y puesta en valor de un patrimonio hidráulico singular: las galerías de agua de Túnez». En: Gómez, José María y Hervás, Rosa María. Patrimonio hidráulico y cultura del agua. Murcia: Fundación Séneca. Campus Mare Nostrum. Agencia Española de Cooperación Internacional para el Desarrollo, 215-226

Hermosilla, J. e IrAnzo, E. (2014). «Claves geográficas para la interpretación del patrimonio hidráulico mediterráneo. A propósito de los regadíos históricos valencianos». Boletín de la Asociación de Geógrafos Españoles, 66, 49-66. Recuperado de <https://www.age-geografia.es/ojs/index.php/bage/article/view/1779/1695>.

Hermosilla, J.; Iranzo, E.; Pérez, A.; Antequera, M. y Pascual, J. A. (2004). «Las galerías drenantes de la provincia de Almería. Análisis y clasificación tipológica». Cuadernos de Geografía, 76. 125-154. Recuperado de <https://ojs.uv.es/index.php/ CGUV/article/view/14414/13189>.

HMidani, Z. y SGUENFle, M. (2018). «Tourist routes at Tafilalet oasis and the prospects of territorial development». International Journal of Scientific Management and Tourism, 4-3, 139-147. 
Iranzo, E.; ANTEquera, M. y Hermosilla, J. (2010). «Identificación, evaluación y puesta en valor de un patrimonio hidráulico singular. Las galerías drenantes de la cuenca del Júcar». Investigaciones Geográficas, 53, 125-143. $<$ https://doi.org/10.14198/INGEO2010.53.06>

LEY 4/2007, de 16 de marzo, de Patrimonio Cultural de la Comunidad Autónoma de la Región de Murcia. Recuperado de <https://www.boe.es/buscar/pdf/2008/ BOE-A-2008-12526-consolidado.pdf $>$.

López, J. A. (2009). El agua y sus usos en el Campo Alto de Lorca (Región de Murcia). Murcia: Asociación Murciana de Ciencia Regional.

- (2015). «Funcionalidad actual de la "Fuente La Mina”. Lorca (Región de Murcia)». Papeles de Geografía, 61, 154-168.

<https://doi.org/10.6018/geografia/2015/208891>

- (2018). «Antiguos molinos hidráulicos en la Región de Murcia. Un nuevo enfoque turístico y patrimonial». Cuadernos Geográficos, 57 (2), 326-349. <http://dx.doi.org/10.30827/cuadgeo.v57i2.5977>

- (2020a). «La situación de las galerías drenantes en la Región de Murcia». Cuadernos Geográficos, 59 (3), 304-324.

<http://dx.doi.org/10.30827/cuadgeo.v59i3.13464>

- (2020b). «Galerías de agua en el Campo Alto de Lorca (Región de Murcia). Análisis y caracterización territorial». Investigaciones Geográficas, 73, 235-256. <https://doi.org/10.14198/INGEO2020.LF>

López, J. A.; GÓmeZ, J. M. ${ }^{a}$ y GiL, E. (2015). «Proyectos para aumentar el caudal en el nacimiento del río Mula a través de la técnica del pozo horizontal». Revista Murciana de Antropología, 22, 137-160. Recuperado de <https://revistas.um.es/ $\mathrm{rmu} /$ article/view/241031/183221>.

LÓPEZ-CAMACHO, B. (2001). «Galerías de captación de agua en la Europa mediterránea». Revista de Obras Públicas, 3.414, 121-126. Recuperado de <http://ropdigital.ciccp. es/detalle_articulo.php? registro=18210\&anio=2001\&numero_revista=3414>.

López-Camacho, B.; Bustamante, I. e Iglesias, J. A. (2005). «El viaje de agua (qanat) de la Fuente Grande de Ocaña (Toledo). Pervivencia de una reliquia hidráulica». Revista de Obras Públicas, 3.451, 43-54. Recuperado de <http://ropdigital.ciccp.es/ detalle_articulo.php? registro $=18114 \&$ numero_revista $=3451 \&$ anio $=2005 \&$ anio_ ini $=2000 \&$ anio_fin $=2009>$.

López, F. y SÁnCHEZ, M. C. (2010). «Manantiales de la comarca del Noroeste de la Región de Murcia. Un patrimonio natural amenazado». Papeles de Geografía, 51-52, 169-188. Recuperado de <https://revistas.um.es/geografia/article/view/114491>.

LuO, L.; Wang, X.; GuO, H.; LiU, C.; LiU, J.; Li, L.; Du, X. y QIAN, G. (2014). "Automated Extraction of the Archaeological Tops of Qanat Shafts from VHR Imagery in Google Earth». Remote Sensing, 6 (12), 11.956-11.976. <https://doi.org/10.3390/rs61211956>

Mächtle, B.; Hecht, S.; Nicola Manke, N.; Bernd Kromer, B.; Susanne LinDAuer, S.; LiYing, C.; Wang, L. y Bubenzer, O. (2019). "The Age and Origin of Karez Systems of Silk Road Oases around Turpan, Xinjiang, P. R. of China». En: YANG, L.; Bork, H. R.; FANG X. y MischKe, S. (eds.). Socio-Environmental Dynamics along the Historical Silk Road. Cham: Springer, 359-378. <https://doi.org/10.1007/978-3-030-00728-7_17>

MARTí, R. (1989). "Oriente y occidente en las tradiciones hidráulicas medievales». En: El agua en zonas áridas: arqueología e historia (I Coloquio de Historia y Medio Físico). Almería: Instituto de Estudios Almerienses. Departamento de Historia, 421-440. 
Mayordomo, S. y Hermosilla, J. (2019). «Evaluación del patrimonio cultural: la Huerta de Valencia como recurso territorial». Boletín de la Asociación de Geógrafos Españoles, 82, 2.790, 1-57. <http://dx.doi.org/10.21138/bage.2790>

MECD (2012). «Plan Nacional de Paisaje Cultural». Ministerio de Educación, Cultura y Deporte. Recuperado de <http:/www.culturaydeporte.gob.es/planesnacionales/dam/jcr:da397288-43a3-4ba4-ad32-7e279d29c953/folleto-leer-planpaisaje.pdf $>$.

Megdiche-Kharrat, F.; Ragala, R. y Moussa, M. (2019). «Promoting a sustainable traditional technique of aquifer water acquisition common to arid lands: A case study of Ghassem Abad Qanat in Yazd Province (Iran)». Water Science and Technology: Water Supply, 19 (2), 527-535. $<$ https://doi.org/10.2166/ws.2018.098>

Morales, F. J. (2007). Agua y paisaje en Yecla. Yecla: Ayuntamiento de Yecla.

MuÑoz, A. (2012). "Las "khettaras" del Tafilalet en Marruecos». Tierra y Tecnología: Revista de Información Geológica, 41, 14-18.

Murcia, A. (1958). Aguas subterráneas. Prospección y alumbramiento para riegos. Serie I. Manuales técnicos (18). Publicaciones del Ministerio de Agricultura.

Palerm, J. (2004). «Las galerías filtrantes o qanats en México. Introducción y tipología de técnicas». Agricultura, Sociedad y Desarrollo, I (2), 133-145. Recuperado de <https://www.revista-asyd.mx/index.php/asyd/article/view/1031>.

Pelegrín, M. C. (2006). "Obras hidráulicas históricas de Lorca». Revista Alberca, 4, 165-171. Recuperado de <http://www.amigosdelmuseoarqueologicodelorca.com/ alberca/pdf/alberca4/articulo10.pdf>.

- (2010). «El abastecimiento de agua potable a Lorca hace 80 años». Revista Alberca, 8, 181-188. Recuperado de <http://www.amigosdelmuseoarqueologicodelorca. com/alberca/pdf/alberca8/ALBERCA8_CAP_09.pdf>.

Pelegrín, M. C. y García, E. (2007). «Reseña histórica e hidrológica de la presa de Valdeinfierno y manantial de los Ojos de Luchena (Lorca, Murcia)». Comité Nacional Español de Grandes Presas.

PÉreZ, M. ${ }^{a}$ T. (2005). «Sistemas hidráulicos en el Mediterráneo español y el norte de África, 1840-50 / 2000». Mediterráneo e Historia Económica, 7, 57-79.

Pocklington, R. (1988). «Toponimia y sistemas de agua en Sharq al-Andalus». En: Agua y poblamiento musulmán. Benisa, 103-114.

REMINI, B.; KECHAD, R. y ACHOUR, B. (2014). "The collecting of groundwater by the qanats: a millennium technique decaying». Larhyss Journal, 20, 259-277.

RoDríguEZ, T. (1995). «Evaluación de reservas y recursos hídricos y normas de explotación generales del acuífero Pericay-Luchena (Murcia)». Murcia: Tabala SL.

Ron, Z. (1996). «Sistema de manantiales y terrazas irrigadas en las montañas mediterráneas». En: Agricultura y regadío en Al-Andalus (II Coloquio de Historia y Medio Físico). Almería: Instituto de Estudios Almerienses y Grupo de Investigación Toponimia, Historia y Arqueología del Reino de Granada, 386-408.

RoTH, D. y SCHÜTT, B. (2001). «Las galerías con lumbreras (qanats): obras maestras de la ingeniería rural amenazada». Revista Velezana, 20, 53-64.

SAntamarta, J. C. (2009). "La minería del agua en el Archipiélago Canario». De Re Metallica, 12, 1-8. Recuperado de <https://dialnet.unirioja.es/ejemplar/358494>.

UNESCO (2019). "Qué es el patrimonio cultural inmaterial». Organización de las Naciones Unidas para la Educación, la Ciencia y la Cultura. Recuperado de $<$ https://ich.unesco.org/es/que-es-el-patrimonio-inmaterial-00003>. 
- (1972). «Convención sobre la Protección del Patrimonio Mundial Cultural y Natural 1972». Organización de las Naciones Unidas para la Educación, la Ciencia y la Cultura. Recuperado de <http://portal.unesco.org/es/ev.php-URL_ ID $=13055 \&$ URL_DO=DO_TOPIC\&URL_SECTION=201.html $>$.

Valipour, M.; Ahmed, A.; Antoniou, G.; Sala, R.; Parise, M.; Salgot, M.; Bensi, N. y ANGELAKIS, A. (2020). «Sustainability of Underground Hydro-Technologies: From Ancient to Modern Times and toward the Future». Sustainability, 12, 8.983. $<$ https://doi.org/10.3390/su12218983>

VIDAL, M. J. (1989). «Viajes de agua en Madrid. Una perspectiva actual. Los paisajes del agua». En: Libro jubilar al profesor Antonio López Gómez. Universidad de Valencia-Universidad de Alicante, 265-274.

Voudouris, K.; Valipour, M.; Kaiafa, A.; Yun, X.; Kumar, R.; Zanier, K.; KoloKYTHA, E. y ANGELAKIS, A. (2019). «Evolution of water wells focusing on Balkan and Asian civilizations». Water Science \& Technology: Water Supply, 19 (2), $347-$ 364. <https://doi.org/10.2166/ws.2018.114>

WiLKINSON, J. C. (1977). Water and tribal settlement in South-East Arabia, a study of the Aflaj of Oman. Oxford: Clarendon Press.

ZIVDAR, N. y KaRIMIAN, A. (2020). «Integrative Conservation of Tehran's Oldest Qanat by Employing Historic Urban Landscape Approach». En: The Urban Book Series, 207-277. 
